\title{
Genotype, Temperature, and Sampling Date Affect Embryogenesis in Asparagus Anther Culture
}

\author{
David J. Wolyn and Xiaorong Feng \\ Department of Horticultural Science, University of Guelph, Guelph, Ontario \\ N1G 2W1, Canada
}

Additional index words. Asparagus officianalis, embryo, haploid, breeding

\begin{abstract}
Asparagus (Asparagus officinalis L.) anthers from flowers of field-grown plants were cultured for five genotypes, four incubation temperatures, and three sampling dates. Treatments were evaluated for total and embryogenic callus production. Incubating anthers at $35 \mathrm{C}$ was optimal for initiating embryogenic callus for three genotypes. Another line performed best and equally well at 29 and $32 \mathrm{C}$, while one was recalcitrant to embryogenic callus formation at the temperatures evaluated. For all genotypes, almost half of the anthers produced callus for at least one temperature treatment, hut the percentage of these calli that was embryogenic ranged from $0 \%$ to $50 \%$. Sampling date affected response only for specific genotype-temperature combinations. Embryo recovery ranged from six to 14 per callus. For the four responsive genotypes, $77 \%$ to $100 \%$ of plantlets was haploid. Culturing anthers at several temperatures ranging from 29 to $35 \mathrm{C}$, with repeated samplings of flowers from the field, likely will allow recovery of haploid embryos from many selections. This result will expand the germplasm base to develop all-male asparagus hybrids.
\end{abstract}

Asparagus is a dioecious perennial in which gender is controlled by a single gene, $M$; males are $M m$ and females are $m m$ (Rick and Hanna, 1943; Sneep, 1953). Breeding efforts focus on developing all-male hybrids produced by crossing a female and a supermale $(M M)$. Although supermales can be obtained from the progeny of occasional hermaphroditic flowers on male plants, producing perfect flowers is genotype- and environment-dependent. Recovering doubled haploid supermales through anther culture may enhance breeding efforts and expand the germplasm base to develop all-male hybrids.

Anther culture has been used to obtain doubled haploid asparagus (Doré, 1974; Falavigna et al., 1985; Hondelman and Wilberg, 1973; Hsu et al., 1988; Inagaki et al., 1983; Pelletier et al., 1972; Rotondo, 1984; Tsay and Hsu, 1986; Tsay et al., 1982; Yakuwa et al., 1972). Efficiency was often low; fewer than 10 plants were recovered per 100 anthers cultured (Falavigna et al., 1990; Tsay and Hsu, 1986 ) and $\leq 10 \%$ of the plants was haploid (Falavigna et al., 1985; Hsu et al., 1988; Torrey and Peirce, 1984; Tsay and Hsu, 1986). Response also depended on genotype; $0 \%$ to $93 \%$ of anthers produced calli and $0 \%$ to $31 \%$ of calli produced shoots (Qiao and Falavigna, 1990; Tsay and Hsu, 1986; Tsay et al., 1982).

Significant genotypic and environmental effects for anther culture response have been

Received for publication 27 July 1992. Accepted for publication23 Oct. 1992. The cost of publishing this paper was defrayed in part by the payment of page charges. Under postal regulations, this paper therefore must be hereby marked advertisement solely to indicate this fact. identified in various species. Embryo recovery per anther ranged from four to 196 for rapeseed (Brassica napus L.) genotypes surveyed (Chuong et al., 1988). In barley (Hordeum vulgare L.) anther culture, $73 \%$ and $11 \%$ of the total variation observed were explained by genotypic and environmental effects, respectively (Knudsen et al., 1989).

Recently, we reported that $15 \%$ of anthers for the G203 genotype incubated at 32C produced embryogenic calli (Feng and Wolyn, 1991). Each callus produced 10 to 15 embryos, of which $50 \%$ germinated and $76 \%$ was haploid. The objective of the study reported here was to determine the effects of genotype, incubation temperature, and sampling date on producing haploid embryos in asparagus anther culture.

Field-grown flowers with microspores at the late uninucleate developmental stage were collected on 10 and 24 July and 10 Aug. 1991 for genotypes G127, G133, G171, G193, and G203 and stored at $5 \mathrm{C}$ for $24 \mathrm{~h}$. Anther culture was conducted as described by Feng and Wolyn (1991), except initial incubation temperatures varied. Anthers were placed on a solid MS (Murashige and Skoog, 1962) medium containing $\left(\mathrm{mg} \cdot\right.$ liter $\left.^{-1}\right) 500$ casein hydrolysate, 800 glutamine, $2 a$ - naphthalenacetic acid (NAA), $1 \mathrm{~N}^{6}$-benzyladenine (BA), and 5\% sucrose and incubated at $26,29,32$, or $35 \mathrm{C}$ for 4 weeks in darkness. All treatments had four replications, each consisting of a petri plate with 18 anthers. Calli were grown at $25 \mathrm{C}$ for 4 weeks with a 16$\mathrm{h}$ photoperiod. Subsequently, developing embryos and calli were transferred to embryo maturation medium [MS containing (mg.liter ${ }^{-1}$ ) 0.1 NAA, 0.1 kinetin, $0.65 a$-cyclopropyl- $a$ (4-methoxyphenyl)-5-pyrimidinemethanol (ancymidol), and 6\% sucrose] for 4 weeks.
Embryos were germinated on MS containing $1 \mathrm{mg}$ gibberellic acid $\left(\mathrm{GA}_{3}\right) /$ liter.

Calli were classified as embryogenic or nonembryogenic. The number of embryos per embryogenic callus was determined. Chromosomes from randomly selected plants for each genotype were counted according to Grant (1982) with carbol fuchsin stain (Zhu, 1982).

Data for the number of embryogenic callitransformed and nontransformed values-were not distributed normally; many replications had zero values. Consequently, means and standard errors are presented.

Genotype, incubation temperature, and sampling date affected the total and embryogenic number of calli in asparagus anther culture (Table 1). For the most responsive genotypes at their optimum temperatureG127 and G203 at 35C-half of the anthers produced calli and $\approx 50 \%$ of the calli was embryogenic. The response at this temperature was consistent for the three sampling dates. G171 anthers rarely produced embryogenic calli, although $50 \%$ produced green or brown calli at 29 and 32C. About $10 \%$ of G133 and G193 anthers produced embryogenic calli; optimum response was observed at $35 \mathrm{C}$ for the former and at 29 and $32 \mathrm{C}$ for the latter.

The proportion of total calli that was embryogenic differed among temperature treatments for some genotypes. Similar numbers of embryogenic calli were produced at 26, 29, and 32C for G193, although the number of total calli varied twofold. Total callus recovery for G203 anthers incubated at 32 and 35C was similar, while the number of embryogenic calli ranged from 1.0 to 5.4.

Sampling date affected total and embryogenic callus formation for specific genotypetemperature combinations. The response of G127, G133, and G171 anthers collected on 10 July was lower than that for other sampling dates for certain temperature treatments. The G203 genotype was not affected substantially by sampling date.

The number of embryos produced per embryogenic callus, pooled for temperature treatments and sampling dates, was $9.7 \pm 0.5$ for $\mathrm{G} 127,10.3 \pm 0.6$ for $\mathrm{G} 133,6.0 \pm 1.2$ for G171, $13.9 \pm 1.3$ for G193, and $13.4 \pm 0.6$ for G203. Since interactions were observed among genotypes, incubation temperatures, and sampling dates for callus formation, these data are presented only to indicate the potential embryo yield. For the five genotypes, germination ranged from $45 \%$ to $58 \%$. Tomaximize the recovery of genetically distinct haploids for a breeding program, one would use a single plant from a callus; multiple embryos on a callus could have arisen from the same microspore.

Most ( $77 \%$ to $100 \%$ ) plants sampled randomly for four of the five genotypes were haploid (Table 2). Few embryos were produced from G171; however, many diploid plantlets were obtained through organogenesis from green, nonembryogenic calli.

When data from these experiments were compared withthose from initial studies (Feng and Wolyn, 1991), the response of G203 at $32 \mathrm{C}$ varied between years. For experiments 
Table 1. Effects of genotype, incubation temperature, and sampling date on total and embryogenic callus formation in asparagus anther culture.

\begin{tabular}{|c|c|c|c|c|c|c|}
\hline \multirow[b]{2}{*}{ Genotype } & \multirow{2}{*}{$\begin{array}{c}\text { Sampling } \\
\text { date }\end{array}$} & \multirow{2}{*}{$\begin{array}{c}\text { Callus } \\
\text { type }^{2}\end{array}$} & \multicolumn{4}{|c|}{ Incubation temp $\left({ }^{\circ} \mathrm{C}\right)$} \\
\hline & & & 26 & 29 & 32 & 35 \\
\hline \multirow{7}{*}{ G127 } & & & No. calli & & & \\
\hline & 10 July & Tot & $0.3 \pm 0.2^{x}$ & $0.5 \pm 0.2$ & $0.9 \pm 0.3$ & $8.9 \pm 0.5$ \\
\hline & & Emb & $0.0 \pm 0.0$ & $0.2 \pm 0.1$ & $0.1 \pm 0.1$ & $5.6 \pm 0.8$ \\
\hline & 24 July & Tot & $2.3 \pm 0.8$ & $3.1 \pm 0.7$ & $4.7 \pm 0.6$ & $9.0 \pm 0.3$ \\
\hline & & Emb & $0.0 \pm 0.0$ & $0.1 \pm 0.1$ & $1.2 \pm 0.3$ & $5.3 \pm 0.5$ \\
\hline & 20 Aug. & Tot & -- & --- & $3.5 \pm 0.5$ & $11.0 \pm 0.4$ \\
\hline & & Emb & & & $0.5 \pm 0.5$ & $4.0 \pm 0.9$ \\
\hline \multirow[t]{4}{*}{ G133 } & 10 July & Tot & $0.4 \pm 0.2$ & $2.8 \pm 0.4$ & $3.4 \pm 1.0$ & $6.9 \pm 0.3$ \\
\hline & & $\mathrm{Emb}$ & $0.0 \pm 0.0$ & $0.0 \pm 0.0$ & $0.0 \pm 0.0$ & $1.2 \pm 0.3$ \\
\hline & 24 July & Tot & $5.4 \pm 1.3$ & $9.1 \pm 1.4$ & $9.2 \pm 0.8$ & $8.5 \pm 0.6$ \\
\hline & & Emb & $0.0 \pm 0.0$ & $0.6 \pm 0.3$ & $0.2 \pm 0.2$ & $2.2 \pm 0.4$ \\
\hline \multirow[t]{6}{*}{ G171 } & 10 July & Tot & $3.9 \pm 0.6$ & $8.4 \pm 0.6$ & $9.4 \pm 0.6$ & $2.8 \pm 0.4$ \\
\hline & & $\mathrm{Emb}$ & $0.1 \pm 0.1$ & $0.0 \pm 0.0$ & $0.0 \pm 0.0$ & $0.0 \pm 0.0$ \\
\hline & 24 July & Tot & $11.3 \pm 0.6$ & $15.5 \pm 0.4$ & $10.6 \pm 0.5$ & $9.4 \pm 1.1$ \\
\hline & & Emb & $0.0 \pm 0.0$ & $0.0 \pm 0.0$ & $0.2 \pm 0.2$ & $0.1 \pm 0.1$ \\
\hline & 20 Aug. & Tot & $12.0 \pm 1.1$ & $14.8 \pm 1.7$ & $12.3 \pm 0.6$ & $10.0 \pm 1.2$ \\
\hline & & Emb & $0.1 \pm 0.1$ & $0.0 \pm 0.0$ & $0.0 \pm 0.0$ & $0.0 \pm 0.0$ \\
\hline \multirow[t]{2}{*}{ G193 } & 20 Aug. & Tot & $9.6 \pm 0.4$ & $10.1 \pm 0.5$ & $4.9 \pm 0.4$ & $1.9 \pm 0.5$ \\
\hline & & Emb & $1.4 \pm 0.4$ & $2.0 \pm 0.5$ & $2.2 \pm 0.2$ & $0.2 \pm 0.2$ \\
\hline \multirow[t]{4}{*}{ G203 } & 10 July & Tot & $1.6 \pm 0.4$ & $6.4 \pm 0.8$ & $7.3 \pm 0.7$ & $8.0 \pm 0.5$ \\
\hline & & Emb & $0.1 \pm 0.1$ & $0.8 \pm 0.4$ & $1.0 \pm 0.2$ & $4.2 \pm 0.9$ \\
\hline & 24 July & Tot & $2.8 \pm 0.4$ & $5.0 \pm 0.6$ & $8.6 \pm 0.5$ & $10.8 \pm 0.7$ \\
\hline & & $\mathrm{Emb}$ & $0.2 \pm 0.1$ & $1.0 \pm 0.5$ & $1.1 \pm 0.3$ & $6.6 \pm 0.9$ \\
\hline
\end{tabular}

${ }^{2}$ Tot $=$ total calli; Emb = embryogenic calli.

'Eighteen anthers per replication.

Mean \pm SE.

Table 2. Ploidy of plants recovered in asparagus anther culture from embryogenic callus.

\begin{tabular}{lcccc}
\hline \hline Genotype & No. plants & $\begin{array}{c}\text { Haploid } \\
(\%)\end{array}$ & $\begin{array}{c}\text { Diploid } \\
(\%)\end{array}$ & $\begin{array}{c}\text { Tetraploid } \\
(\%)\end{array}$ \\
\hline G203 & 10 & 90 & 10 & 0 \\
G193 & 13 & 77 & 23 & 0 \\
G171 & 12 & 0 & 92 & 8 \\
G133 & 6 & 100 & 0 & 0 \\
G127 & 21 & 78 & 22 & 0 \\
\hline
\end{tabular}

${ }^{\mathrm{x}}$ Plants recovered only from green, nonembryogenic callus.

conducted in 1990 at $32 \mathrm{C}$ with three sampling dates, $\approx 45 \%$ of anthers produced calli, of which $30 \%$ was embryogenic. When the same treatment was repeated for two sampling dates in $1991,41 \%$ to $48 \%$ of anthers produced calli, but only $13 \%$ to $14 \%$ was embryogenic. Since the effects were consistent for sampling dates in a given year, the physiological status of the plant may have differed between seasons to produce these results.

Anthers from new selections or from specific genotypes in different years should be cultured at several incubation temperatures ranging from 29 to $35 \mathrm{C}$. Since a genotype was recalcitrant for the procedure outlined here, additional modifications may be necessary to recover doubled haploids from all selections. Despite the effects of sampling date for callus production from anthers of field-grown flowers, we recommend them for anther culture; more anthers from field-grown flowers produced embryogenic callus than those from the greenhouse (Feng and Wolyn, 1991). Although interactions between genotype, temperature, sampling date, and years were observed for response in anther culture, haploid embryos were produced for several breeding selections; thus, the supermale germplasm available for developing all-male hybrid asparagus cultivars was expanded.

\section{Literature Cited}

Chuong, P.V., C. Deslauriers, L.S. Kott, and W.D. Beversdorf. 1988. Effect of donor genotype and bud sampling on microspore culture of Brassica napus. Can. J. Bot. 66:1653-1657.

Doré, C. 1974. Production de plantes homozygotes mâles et females à partir d'anthères d'asperge, cultivées in vitro. CR. Acad. Sci. Paris. 278D:2135-2138.

Falavigna, A., P.E. Casali, and M.G. Tacconi. 1990. Potential of in vitro anther culture technique for asparagus breeding in Italy. Acta Hort. 271:3946.

Falavigna, A., M.G. Tacconi, and P.E. Casali. 1985. Asparagus breeding through anther in vitro cul- ture, eight years of activity in Italy, p. 3 1-40. In: E.C. Lougheed and H. Tiessen (eds.). Proc. Sixth Intl. Asparagus Symp., Univ. of Guelph, Guelph, Ont., Canada, 5-9 Aug. 1985.

Feng, X.R. and D.J. Wolyn. 1991. High frequency production of haploid embryos in asparagus anther culture. Plant Cell Rpt. 10:574-578.

Grant, W.F. 1982. Plant mutagen assays based on chromosome mutations, p. 10-11. In: E.J. Klekowski (ed.). Environmental mutagenesis, carcinogenesis and plant biology. vol. II. Praeger, New York.

Hondelmann, W. and B. Wilberg. 1973. Breeding all-male varieties of asparagus by utilization of anther and tissue culture. Z. Pflanzenzüchtg 69:19-24.

Hsu, J.Y., C.C. Yeh, and H.S. Tsay. 1988. The breeding of all male asparagus plants by means of anther culture, p. 153-163. In: S-C. Lin and Y-F. Yen (eds.). Proc. Fourth Symp. Asparagus Res. in Taiwan, Tainan Dist. Agr. Sta., Taiwan, 7-9 Jan. 1988

Inagaki, N., T. Harada, and T. Yakuwa. 1983. Studies on the anther culture of horticultural crops VII: Investigation of optimal conditions for obtaining pollen-originating callus and its characteristics- in Asparagus officinalis L. J. Faculty Agr. Hokkaido Univ. 61:279-285.

Knudsen, S., I.K. Due, and S.B. Andersen. 1989. Components ofresponse in barley anther culture. Plant Breeding 103:241-246.

Murashige, T. and F. Skoog. 1962. A revised medium for rapid growth and bioassays with tobacco tissue cultures. Physiol. Plant. 15:473-497.

Pelletier, G., C. Raquin, and G. Simon. 1972. La culture in vitro d'anthères d'Asperge (Asparagus officinalis). C.R. Acad. Sci. Paris 274D:848851.

Qiao, Y.M. and A. Falavigna. 1990. An improved in vitro anther culture method for obtaining doubled-haploid clones of asparagus. Acta Hort. 271:145-157.

Rick, C.M. and G.C. Hanna. 1943. Determinationof sex in Asparagus officinalis L. Amer. J. Bot. 30:711-714.

Rotondo, G.G. 1984. Embryogenesis in microspores of Asparagus officinalis L. cv. Viking via anther culture. MS Thesis, Univ. of Guelph, Guelph, Ont., Canada.

Sneep, J. 1953. The significance of andromonoecy for the breeding of Asparagus officinalis $\mathrm{L}$. Euphytica 2:89-95.

Torrey, D.D. and L.C. Peirce. 1984. Anther culture of asparagus cv. Emerald. Asparagus Res. Nwsl. 2:22-26.

Tsay, H.S. and J.Y. Hsu. 1986. The breeding of all male asparagus plants by means of anther culture. Taiwan Asparagus Res. 1983-85:23-26.

Tsay, H.S., P.C. Lai, L.J. Chen, and N.C. Chi. 1982. The development of haploid plant of Asparagus officinalis L. through anther culture. Taiwan Asparagus Res. 1981:23-26.

Yakuwa, T., T. Harada, N. Inagaki, and Y. Shiga. 1972. Studies on anther culture of horticultural crops. I. Induction of callus and differentiation of organs in anther culture of asparagus. J. Jpn. Soc. Hort. Sci. 41:272-280.

Zhu, Z. 1982. Plant chromosome techniques. Academic, Beijing, China. 